\title{
PROPOSAL FOR UNIFYING THE SAFETY AND SECURITY TERMINOLOGY AT THE FACULTY OF SAFETY ENGINEERING OF THE VŠB - TECHNICAL UNIVERSITY OF OSTRAVA
}

\author{
David ŘEHÁK ${ }^{1}$, Zuzana GIERTLOVÁ
}

Review article

Abstract: $\quad$ The proposal for unifying the topical safety and security terminology at the Faculty
of Safety Engineering of the VŠB - Technical University of Ostrava is presented in
the paper. The paper deals with the descriptions of key terms from the area of safety/
security engineering, which reflect all the specialized areas emerging from the priority
specializations of this faculty and makes their comprehension and interconnection easier.
Keywords: $\quad$ Safety; Hazard; Threat; Vulnerability; Risk.

\section{Introduction}

The Faculty of Safety Engineering is the youngest faculty of the VŠB - Technical University of Ostrava. The priority directions of scientific research activities, covering both the areas of Safety and Security, include fire protection, industrial safety, work safety, population protection, protection of critical infrastructure, prevention of serious accidents, environmental security and safety of nanomaterials and nanotechnologies.

\section{Materials and methods}

It follows from the above presented priority directions that there are areas of specialization, which are developed within individual faculty departments and workplaces. The areas of specialization are fire protection, population protection, industrial safety and technical security of personnel and property.

The fire protection specialization deals with material behaviour during fire heat stress, predicting the formation of products of fire and a toxic risk during fire, passive and active systems of fire protection, fire safety devices, fire prevention, fire dynamics, modelling the fire development in closed space, evacuation of personnel, etc. (Activities of Departments, 2011).

Within the population protection, the attention is paid to the management and tactics of getting the emergencies under control, integrated rescue system, crisis management, logistics during crisis states, emergency planning, civil emergency planning and population protection, constructions and facilities of civil protection, etc. (Activities of Departments, 2011).

The area of industrial safety deals with the issues of risk analysis, methodology and application of risk analysis, work and environment safety, analysis of work risks, ergonomics, safety of processes and technologies, counter-explosive protection, risk management in industry, chemical security (in the context of REACH, ATECH, and the abuse of chemical substances), serious accidents including the combined risks and the impacts of accidents on environment, reliability of human factor, the systems of risk management in industry and the techniques of risk reduction, safety in energetics, traffic safety, physical-chemical processes in atmosphere, etc. (Activities of Departments, 2011).

Within the technical security of personnel and property, the attention is paid to the protection of personnel and facilities, security management, protection of buildings of special significance, protection of research organizations, symmetric and asymmetric threats, etc. (Activities of Departments, 2011).

Particular terminology is used in each of the above mentioned areas. However, all these areas are parts of security engineering and therefore they should share common general terminology. The reason is mainly the necessity of mutual communication and cooperation among individual areas. Therefore it has been proposed to define basic terms from the area of security engineering, which would reflect all the above mentioned subareas and make it easier to understand and interconnect them. A number of relevant materials have been used for elaborating the proposed unified safety terminology of the Faculty of Safety Engineering at the VŠB Technical University of Ostrava. The materials may be classified in two groups. The first group of materials includes technical standards and legal amendments. The Czech National Standard called Risk Management (ČSN, 2010) and the Dictionary of Risk Management (Instruction, 2010) may be

VŠB - Technical University of Ostrava, Faculty of Safety Engineering, Ostrava, Czech Republic, david.rehak@vsb.cz

2 Technische Universität München, München, Deutschland, zuzana@giertlova.de 
considered the key materials. Other, more specific materials, include the Czech National Standard called Management Systems of Safety and Health Protection at Work (ČSN, 2008), Act on Integrated Rescue system (Act, 2000a), Act on Crisis Management (Act, 2000b) and Act on the Prevention of Serious Accidents Caused by Selected Hazardous Chemical Substances or Chemical Preparations (Act, 2006). The second group of materials includes mainly specialized publications dealing with the

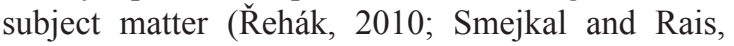
2009; Danihelka and Poledňák, 2008; Mikolaj et al., 2000; Mikolaj et al., 2004; Terminological Dictionary, 2009).

\section{Results}

The following selected terms and their synthetic definitions from the area of security engineering are presented in the next part of the paper: security, protected interest, hazard, source of hazard, hazardousness, threat, endangerment, vulnerability, security measures, emergency, accident, seriousness of consequences, probability, risk, source of risk, residual risk, and risk management.

Security is the state in which a particular subject or an object is without being threatened as far as its existence, interests and values are concerned.

Protected interest represents everything, which has some value for a society. The value may be reduced due to the effect of hazard, i.e. life, health, property, and the environment.

Hazard represents the property, force, event, activity, or a person, which have an impact either directly on the protected interest, or on the security measures with the aim to gain the access to the protected interest. It is also an element, which has potential internal capability of causing risk, either on its own, or in combination with other elements. The prerequisite for the hazard to be effective is its activation, affected by hazard source. The term threat is rather used in the area of state internal and external security.

The source of hazard is a factor, which may activate a given hazard. It is either an external element (e.g. the environment), or an internal system element (e.g. processes, employees, immovable assets), which activate particular hazard and the development and symptoms of which are the causes of possible undesirable impacts on protected interests.

Hazard may be classified into two categories with regard to the impact, which the sources of hazard have on an organization (object or subject as the case may be). The first category includes external hazards.
Such hazards are not susceptible to influence and we can only mitigate their consequences. External hazards may further be subdivided into six areas, i.e. the hazards of political, economic, social, technological, legislative and ecologic nature. Such an analysis is made according to the factors of PESTLE analysis (Grasseová et al., 2010), which is used for the analysis of external environment. The second category includes internal hazards. Such hazards are affectable and we can either minimize or fully eliminate the causes of their impacts. Internal hazards may further be subdivided into three areas, i.e. the hazards of procedural (project), personnel and material nature. The classification into the categories and areas is shown in Fig. 1.

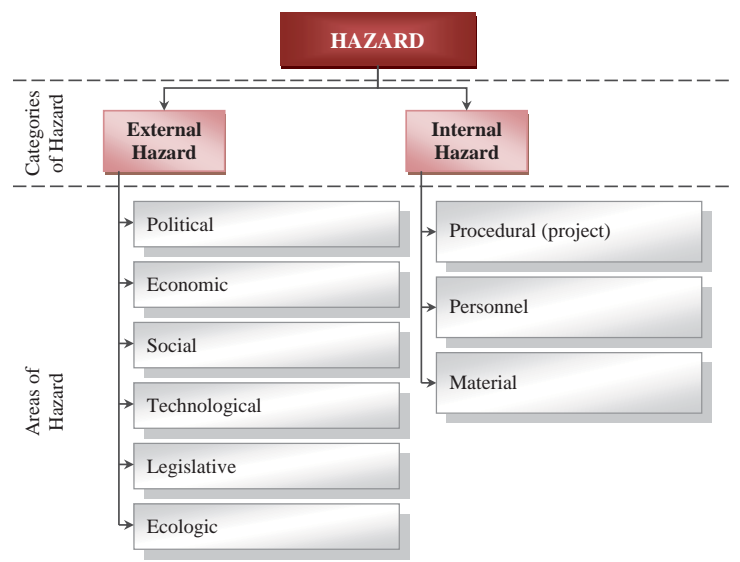

Fig. 1 The Recommended Classification of Hazards into Categories and Areas

Hazardousness represents the internal property or the capability of hazard to cause damage.

Endangerment is the state when hazard has an impact on a protected interest, i.e. when a dangerous situation occurs.

Vulnerability represents deficiency, weak point or the state of protected interest, on which hazard may have an undesirable impact. Vulnerability may also be defined as the level to which the protected interests are prone to damage caused by a particular emergency. The opposite of vulnerability is resistance, which is increased by implementing the security measures.

Security measures are the process or means proposed with the aim to reduce the vulnerability of protected interest or to minimize the impact of hazard. The implementation of security measures increases the resistance of protected interests, or detects the impacts of hazards and mitigates or fully eliminates these impacts on protected interests.

Emergency is a serious, hard to predict and spatially limited event caused by anthropogenic activities, natural impacts and processes threatening 
life, health, property and environment. The term accident is used for the same concept in the area of technological risks.

Seriousness of consequences represents the extent of reduced value or level of protected interest.

Probability is the value expressing the level to which the occurrence of emergency is anticipated.

Risk emerges from mutual interaction of hazard and protected interest and is expressed by the combination (or product) of emergency occurrence probability and its impact on a given protected interest. Risk is also perceived as a quantification level of threat for the protected interest through the impact of hazard.

Risk may be classified into various types according to particular types of hazard, which have impacts on protected interests. It is e.g. political risk, economic risk, social risk, etc. Some specialized publications (Božek and Urban, 2008; Smejkal and Rais, 2009) classify risks according to other classification criteria, such as e.g.:

- predictability, i.e. the predictable and unpredictable risks;

- influence susceptibility, i.e. risks susceptible and non-susceptible to influence;

- origin, i.e. primary and secondary risks; the primary risks are original and the secondary risks are caused by taking the measures to mitigate the primary risks;

- assessment objectivity, i.e. subjective and objective risks;

- emergency development dynamics, i.e. slow and fast risks;

- probability of emergency origin, i.e. probable and improbable risks;

- emergency impact, i.e. risks with low, higher and fatal impacts.

Residual risk is the risk remaining after risk treatment, i.e. after introducing the security measures. The residual risk should be so low that it would not exceed the referential level of risk and be acceptable for the organization to such an extent that it would not be necessary to take further security measures for its reduction.

The relations among the above mentioned terms are shown in Fig. 2.

Risk management represents a continual and systematic process for effective dealing with risks. The risk management consists of five basic subprocesses (see Fig. 3) as it follows:

- communication and consultation;

- establishing the context;
- risk assessment (it includes risk identification, analysis and evaluation),

- risk treatment;

- monitoring and review.

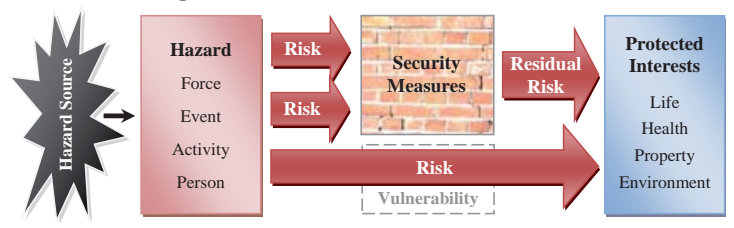

Fig. 2 Relations among Basic Terms in the Area of Safety Engineering

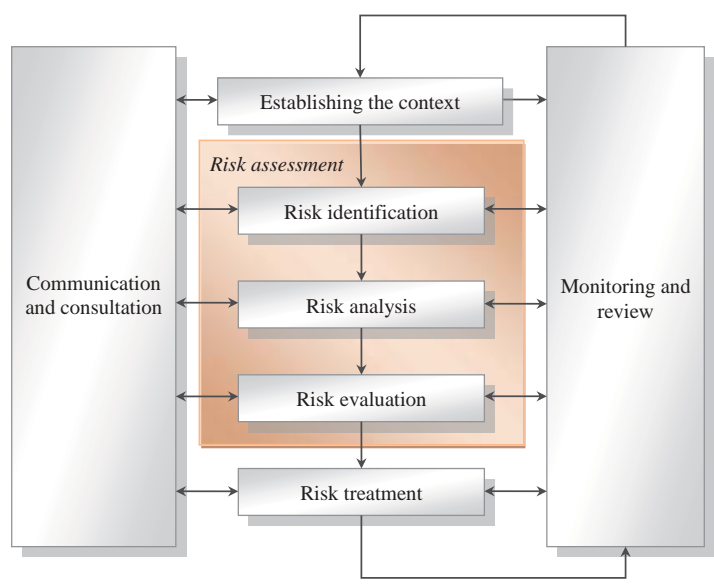

Fig. 3 Process of Risk Management (ČSN ISO 31000:2010)

\section{Conclusion}

Security terminology at the Faculty of Safety Engineering of the VŠB - Technical University of Ostrava includes a number of terms related to basic areas of specialization, such as fire protection, population protection, industrial safety and technical security of personnel and property. Despite the fact that the areas are specific and differ from each other, it is possible to find identical definitions of basic terms in their centres, which clearly makes it easier for us to comprehend and interconnect them and start necessary co-operation.

Finally, I would like to express my thanks to my colleagues from the Faculty of Safety Engineering, who actively participated in compiling the proposed safety and security terminology and whose comments contributed to the objective definition of terms.

\section{Acknowledgements}

The paper has been written as part of the Grant Project on the "Security of Citizens - Crisis Management" sponsored by the Ministry of Interior of the Czech Republic and filed under the code VF20112015018. 


\section{References}

Act No 59/2006 Col. on the Prevention of Serious Accidents Caused by Selected Hazardous Chemical Substances or Chemical Preparations as Amended by Later Regulations. (in Czech).

Act No 239/2000 Col. (2000a), on Integrated Rescue System as Amended by Later Regulations. (in Czech).

Act No 240/2000 Col. (2000b) on Crisis Management as Amended by Later Regulations. (in Czech).

Activities of Departments (2011) [online]. Ostrava: Faculty of Safety Engineering, 2011 [cit. 2011-09-23]. Available at: http://www.fbi.vsb.cz/cs/okruhy/veda-a-vyzkum/odborna-cinnost/cinnost-kateder/ (in Czech).

BOŽEK, František, URBAN, Rudolf (2008). Risk Management - General Part. $1^{\text {st }}$ ed. Brno: University of Defence, 2008. 145 s. ISBN 978-80-7231-259-7. (in Czech).

ČSN ISO 31000:2010. Risk Management - Principles and Regulations. (in Czech).

ČSN OHSAS 18001:2008. Management Systems of Safety and Health Protection at Work - Requirements. (in Czech).

DANIHELKA, Pavel, POLEDŇÁK, Pavel (2008). Risk Analysis - General Approach. Communications - Scientific Letters of the Universtiy of Zilina, 2008, No. 1, pp. 20-23. ISSN 1335-4205.

GRASSEOVÁ, Monika, DUBEC, Radek, ŘEHÁK, David (2010). Enterprise Analysis in Manager's Hands: 33 the Most Commonly Used Methods of Strategic Management. ${ }^{\text {st }}$ ed. Brno: Computer Press, 2010. 325 p. ISBN 978-80-251-2621-9. (in Czech).

Instruction 73:2010. Management of Risks - Dictionary. (in Czech).

MIKOLAJ, Jan, HERŠIC, Ladislav, HITTMÁR, Štefan, HORÁČEK, Jiří, MÍKA, Vladimír, ŠIMÁK, Ladislav (2000). Crisis Management as a Social Science Problem. Žilina: Faculty of Special Engineering of Zilina University, 2000, 139 p. ISBN 80-88829-54-2. (in Slovak).

MIKOLAJ, Ján, HOFREITER, Ladislav, MACH, Vlastimil, MIHÓK, Jozef, SELINGER, Petr (2004). Terminology of Security Management: Monolingual Dictionary. $1^{\text {st }}$ ed. Košice: Multiprint, 2004. 191 p. ISBN 80-9691481-2. (in Slovak).

ŘEHÁK, David (2010). Management of Risks as a Part of Strategic Management. p. 139-176. In GRASSEOVÁ, Monika, DUBEC, Radek, ŘEHÁK, David. Enterprise Analysis in Manager's Hands: 33 the Most Commonly Used Methods of Strategic Management. $1^{\text {st }}$ ed. Brno: Computer Press, 2010. 325 p. ISBN 978-80-251-2621-9. (in Czech).

SMEJKAL, Vladimír, RAIS, Karel (2009). Risk Management in Companies and Other Organizations. $3^{\text {rd }}$ ed. Prague: Grada Publishing, 2009. 360 p. ISBN 978-80-247-3051-6. (in Czech).

Terminological Dictionary of Terms from the Area of Crisis Management and State Defence Planning. $2^{\text {nd }}$ ed. Prague: Ministry of Interior, 2009. 64 p. (in Czech). 